\title{
Presaccadic Brain Potentials in Conditions of Covert Attention Orienting
}

\author{
Maria Slavutskaya ${ }^{1}$ and Valerii V. Shulgovskii ${ }^{2}$ \\ ${ }^{1}$ Laboratory of Comparative Physiology of Higher Nervous Activity \\ ${ }^{2}$ Department of Higher Nervous Activity \\ Moscow State University
}

\begin{abstract}
Twelve healthy subjects underwent investigation of averaged (electroencephalogram) EEG potentials during preparation for motor activity and in the latent period (LP) of visually evoked saccades by presentation of stimuli using Posner's (1980) design of "cost-benefit." It has been shown that covert spatial attention orientation leads to an increase in amplitude and decrease in latency of presaccadic initiation potential peaks within the saccadic latent period (LP) (P-100, N -50). Processes of covert orientation of attention during the interstimulus interval period of anticipation of the target stimulus correlate with the increase of slow negativity of fronto-parietal-temporal localization. Spatial-temporal changes of presaccadic potentials are evidence of the fact that orientation of attention during motor preparation and saccadic initiation is reflected in intensification of fronto-parietal networks of saccadic control and attention, activating the fronto-medio-thalamic and thalamo-parietal modulating systems.

Keywords: orienting of attention, saccades, latent period, presaccadic potentials
\end{abstract}

Se examinaron los potenciales EEG promediados de doce sujetos sanos durante su preparación para actividad motor y en el período latente de sacádicos evocados visualmente por la presentación de estímulos según el diseño de "coste-beneficio" de Posner (1980). Se ha mostrado que la orientación de la atención espacial encubierto lleva a un incremento en la amplitud y un decremento en la latencia de los picos potenciales de iniciación presacádica dentro del período sacádico latente (P-100, N -50). Los procesos encubiertos de orientación de la atención durante el período del intervalo inter-estímulo de anticipación del estímulo meta correlacionan con el incremento de la negatividad lenta de localización fronto-parietal. Cambios espacio-temporales de potenciales presacádicos son evidencia del hecho de que la orientación de la atención durante la preparación motora y la iniciación sacádica se refleja en la intensificación de las redes fronto-parietales de control y atención, activando los sistemas de modulación fronto-medio-talámicos y tálamo-parietales. Palabras clave: orientación de la atención, movimientos sacádicos, periodo latente, potenciales presacádicos

The study was carried out with the support of the Russian Fundamental Research Fund (Project 96-05-4-48259) and the Russian Humanitarian Scientific Fund (Project 04-06-00261a).

Correspondence concerning this article should be addressed to Maria Slavutskaya., Faculty of Biology, Moscow State University, GSP-2, Leninskye gory d.1, str.12, Moscow - 119992 Russia. E-mail: mvslav@yandex.ru and to Valerii V. Shulgovskii, Faculty of Biology MGU, Dpt. Higher Nervous Activity, Phone: +7(495)939-2837, FAX: +7(495)939-2837 Emails: shulg@protein.bio.msu.ru and shulg@mail.ru 
Despite a multitude of studies over the past 40 years, the nature of attention remains poorly understood. An important contribution to the comprehension of attention mechanisms has been made by studies of evoked potentials (Naatanen, 1998; Rutman, 1979), clinical studies using positron emission (PET) and magnetic resonance tomography (fMRT) (Coull, 1998; Mangun, Jha, Hopfinger, \& Handy, 2000; Posner, 1980), as well as neurophysiological studies on monkey neurons (Andersen \& Gnadt, 1989; Robinson, Bowman, \& Kertzman, 1995). The knowledge acquired has permitted the development of hypothetic designs of the interaction of brain structures when attending (Machinskaya, 2003; Coull, 1998; Laberge, 2000; Posner, 1980).

The intimate interrelation of spatial attention and saccadic eye movements is well known, as is their anatomic sharing of these mechanisms (Posner, 1980; Rizzolatti, Riggio, Dascola, \& Umilta, 1987). Several experimental paradigms have been developed in psychophysiology to study the influence of attention on saccadic programming. One of the most adequate paradigms is the method probability of presentation of visual targets of Posner's "cost-benefit" or the "spatial cued task," which permits the quantitative assessment of spatial orientation of attention within a visual field according to the LP of saccadic or manual reaction (Posner, 1980). This method requires the use of signal stimuli to attract attention to one of the visual half-fields. The appearance of peripheral target stimuli (PTS) in the half-field at which attention is aimed leads to a decrease in the LP (benefit) and, in the opposite half-field, to its increase (cost).

Previously, we carried out a study of the magnitude of the LP of saccadic reactions and evoked electroencephalogram (EEG) potentials to setting and signal stimuli using the name method (Slavutskaya, Solovieva, \& Shulgovskii, 2001; Slavutskaya \& Shulgovskiy, 2005). It was revealed that processes of directed attention are reflected in the parameters and topography of the separate components of the potential evoked by switching on the setting and signal stimuli. The study of presaccadic EEG potentials in Posner's (1980) paradigm with their reversed averaging from the beginning of the saccade allows the study of the influence of directed attention on processes of motor preparation and saccade programming.

The aim of the present study is to compare the parameters and topographic distribution of averaged EEG potentials in the saccade LP and the interstimulus period between signal and target stimuli in conditions of directed attention and neutral conditions of probability presentation of visual stimuli using Posner's (1980) cost-benefit method.

\section{Method}

\section{Participants}

Twelve healthy right-handed individuals of ages 20-25 years (7 male and 5 female, university students and staff) with normal eyesight took part in the experiment.

\section{Materials}

Participants sat in a dark room, in an arm chair with a headrest. Unipolar EEG was recorded by the 10-20 international design from the $\mathrm{F} 3, \mathrm{~F} 4, \mathrm{Fz}, \mathrm{Cz}, \mathrm{P} 3, \mathrm{P} 4, \mathrm{Pz}$, $\mathrm{T} 3, \mathrm{~T} 4, \mathrm{O} 1$, and $\mathrm{O} 2$ electrode sites using the EEG $16 \mathrm{~S}$ ("MEDICOR", Hungary; higher limit frequency filter $=70$ $\mathrm{Hz}$, time constant $=0.3 \mathrm{~s}$ ) electroencephalograph. Horizontal eye movements were registered using bipolar oculograms (EOG) with 0.3 time constant. Chaliced electrodes were placed at the external orbital margin.

Control of the experiment, analysis, and storage of data was carried out on a personal computer IBM PC AT -486 in integrated CONANm system. Signal analysis epoch = $5 \mathrm{~ms}$.

\section{Stimuli and Experimental Procedure}

Seven red light diodes served as visual stimuli $(\mathrm{d}=10$ $\mathrm{deg} / \mathrm{min}$ ), located at horizontal and vertical axes of the hemisphere $60 \mathrm{~cm}$ away from the eyes of the participant. Four types of stimuli were used:

1. Central fixation stimulus (CFS);

2. Peripheral target stimuli (PTS), to which the participant was to perform saccades. The stimuli were located at a distance of 10 degrees to the left and right of the central stimulus;

3. Signal stimuli (SS), located at a distance of 5 degrees to the left and right of the central stimuli, indicate the probability of the presentation of target stimuli in the corresponding half-field;

4. Fixation stimuli (FS), located along the vertical axis at a distance of 5 degrees above and below the central stimulus, show the probability of the coincidence of the sides of presentation of signal and target stimuli.

During the same experiment, two experimental designs were used with equal probability: in Design I, conditions of directed attention were presented, with the orientation stimulus located above the FS signaling the presentation of the SS and PTS in the same half-field in $80 \%$ of the cases. Design II presented "neutral" conditions, where the orientation stimulus located below the FS indicated the coincidence of the SS and PTS in the same half-field in $50 \%$ of the cases.

The presentation of visual stimuli was carried out in blocks of 36 presentations in each. The visual stimulation design is displayed in Figure 1. The participant's attention was drawn to the experimental conditions by the method of self-initiation - the participant arbitrarily pressed a button with the right hand, after which one of the orientation stimuli was turned on, with a duration of $100 \mathrm{~ms}$. The switching on of the orientation stimuli coincided with that of the FS, whose duration varied between 900 and 1100 ms with a $100-\mathrm{ms}$ increment. SS of $100 \mathrm{~ms}$ duration were 
turned on simultaneously as the FS was switched off. The peripheral visual stimulus was turned on every $1000-1200$ ms (100-ms increment) after the SS was turned off. The duration of the PTS was $1000-1300 \mathrm{~ms}$ with a $100-\mathrm{ms}$ increment, after which its intensity was decreased by half for $600 \mathrm{~ms}$ ("fading").

Participants were given the following instructions:

Use your right hand to arbitrarily press a button and maintain pressure on it. Fix your gaze on the central stimulus. When the target stimulus is presented, transfer your gaze to it as quickly as possible. As the target stimulus fades, as quickly as possible release the button and return your gaze to the central point. Follow the location of the orientation stimulus closely. Two conditions alternate in the experiment: if at the beginning, the upper orientation signal turns on, the turning on of the signal stimulus will indicate a high probability of the presentation of the target in the same half-field. If the lower orientations stimulus turns on, the target stimulus can occur with equal probability in either half-field.

The experiment commenced after training the participant not to perform involuntary saccades in response to the signal stimuli.

Visual stimuli were presented binocularly. Each participant was presented with 972 to 1080 visual stimuli in three experiments.

\section{Data Analysis}

Using “CONANm" software, individual EEG and EOG data were recorded and analyzed off-line. Saccadic LP of the display screen was measured as the distance between the cursor position at the moment of turning on the PTS

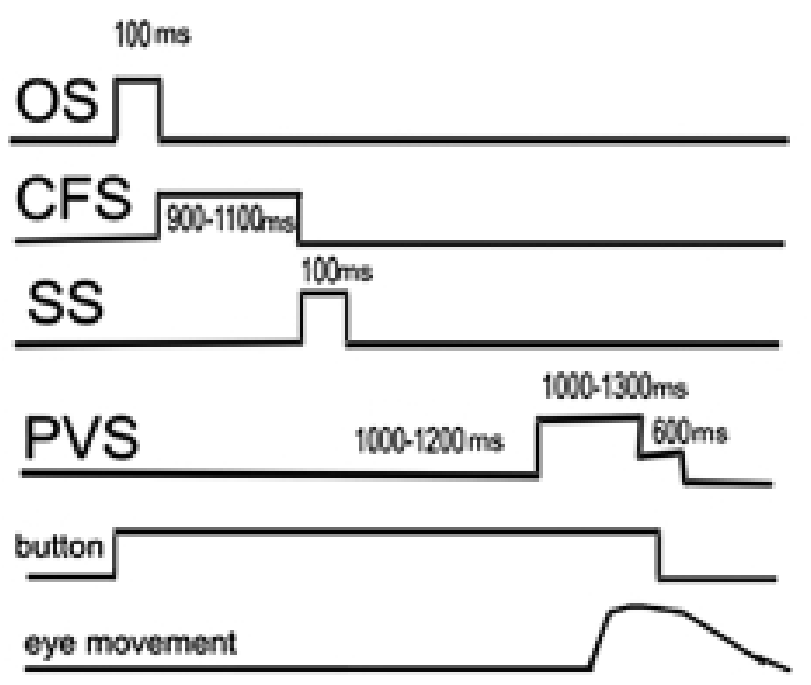

Figure 1. Visual stimulation design. OS = orientation stimulus; SS = signal stimulus; PVS = peripheral visual stimulus. and the viewfinder placed at the point of EOG inflexion, corresponding to the beginning of the saccade. An additional criterion for the beginning of the saccade was the spike potential peak on EEG.

For each subject, selective reverse EEG averaging was carried out prior to saccade with mean LP magnitude (mode $\pm 20 \mathrm{~ms}$ ). The trigger for averaging was the beginning of the saccade according to EOG, coinciding with the spike potential peak on EEG. Zero line was placed at the segment $500-0 \mathrm{~ms}$ to saccade beginning. The average interval was established at $1300 \mathrm{~ms}(800 \mathrm{~ms}$ prior to and $500 \mathrm{~ms}$ following saccade beginning). For the analysis of quick EEG potentials within the LP of the saccade of $100 \mathrm{~ms}$, additional filtration of averaged EEG records was used, with upper limit of $30 \mathrm{~Hz}$, and $5 \mathrm{~Hz}$ for the analysis of slow potentials within the interstimulus period. Premotor negativity was analyzed in the interval between signal and peripheral stimuli. The amplitude of presaccadic potentials was measured relative to zero line. Presaccadic potential peak latency was measured as the distance from saccadic beginning to maximum deflection of the potential for zero line. Depending on the subject, 20-40 stimuli were averaged. The number of stimuli presented for averaged EEG potentials with directed attention and in neutral conditions was the same for all subjects. Furthermore, similar averaging of EEG was carried out for the group of subjects as a whole. For more detailed study of the spatial-temporal changes in amplitude of averaged EEG potentials, the method of computerized graphic mapping with 10-ms increment was used. For each participant's data, the number of foci of positive and negative potentials in the specific zones of their occurrence was calculated.

Standard statistical analysis of data was carried out using STADIA 6.1 statistic software. Significance of mean differences was calculated using Wilcoxon's nonparametric paired criteria because of the limited amount of subjects and, accordingly, the possibility of a different from normal distribution of individual values.

\section{Results}

The magnitude of the saccadic LP of all subjects varied between 80 to $395 \mathrm{~ms}$. A significant diminution of mean saccadic LP values at 13-16 ms was established in conditions of directed attention in comparison to neutral conditions (benefit, $p<.05$ ). However, there were some individual distinctions: 2 subjects out of the 12 showed no such regularity; 3 subjects' decrease in saccadic LP with directed attention was noted only in the left half-field; in another 3 subjects, only in the right half-field. Detailed analysis of the values of saccadic LP under conditions of the present experiment has been cited previously (Slavutskaya et al., 2002). 
As observed in Figure 2, in reverse EEG potential averaging, all subjects showed defined potentials in the saccadic LP, related to saccade initiation- $-\mathrm{P}-1, \mathrm{~N}-1-$ and spike potentials (SP). In order to compare the influence of covert attention orientation on the parameters of presaccadic EEG potentials, only stimuli with a decrease in LP magnitude in conditions of directed attention were analyzed, in comparison to neutral conditions. Statistical analysis did not show any dependence of the magnitude of amplitude and latency of presaccadic potential peaks on saccade directions and therefore, their values were united.

Comparison of the amplitude and latency of the studied peaks showed a significant difference in the parameter of all studied potentials in the various experimental conditions. With directed attention, there was a significant increase in amplitude and a decrease in latency of the peaks in comparison to neutral conditions (see Figure 3).

The mean amplitude of the $\mathrm{N}-1$ potential in target and neutral conditions was $-2.1 \pm 0.25$ and $1.45 \pm 0.25 \mu \mathrm{V}$, respectively $(p<.005)$, and peak latency was $60.5 \pm 7$ and $70.5 \pm 7(p<.05)$. Individual amplitude values of the $\mathrm{N}-1$ potential varied from 0.7 to $4 \mu \mathrm{V}$, and peak latency, from

a

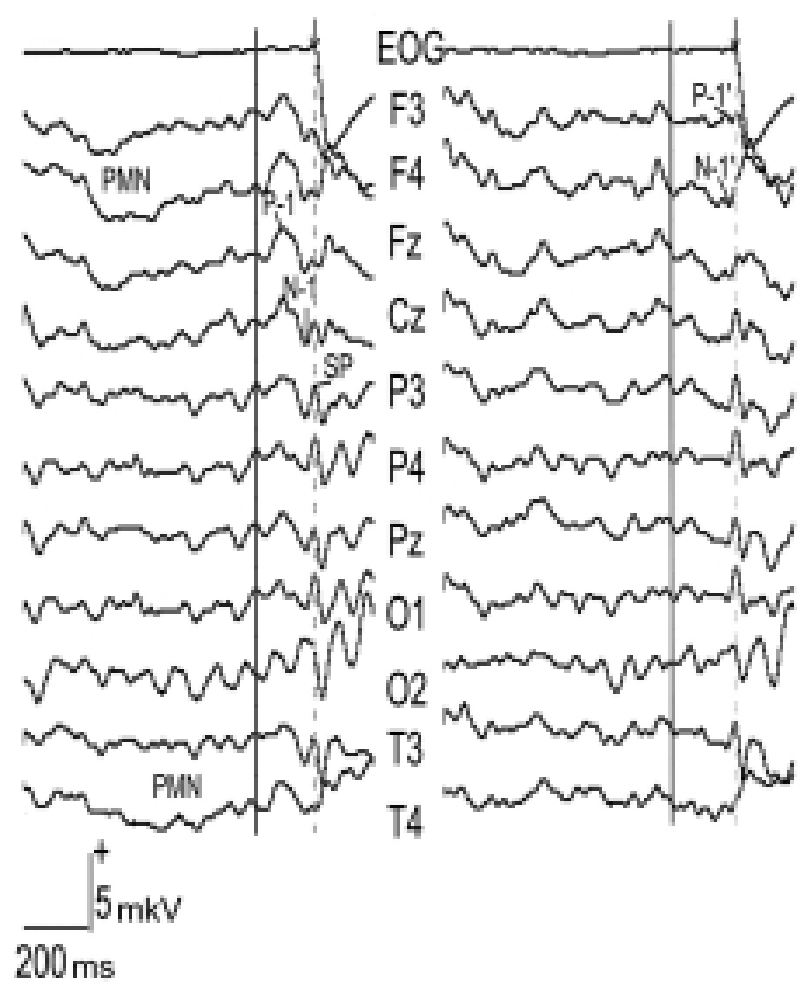

Figure 2. Averaged EEG potential graphs prior to saccade to the left in Design I (a) and Design II (b) in Participant B.D. Averaging trigger (beginning of saccade) is noted with an arrow on the EOG channel. Averaged number $-\mathrm{n}=35$. Solid vertical line corresponds to the conditional beginning of the saccade LP, the dotted line = saccade beginning.
50 to $85 \mu \mathrm{V}$. Foci of maximum amplitude of various subjects were noted in frontal and occipital regions. In $84 \%$ of the cases, the focus of the $\mathrm{N}-1$ potential was located in the hemisphere contralateral to the saccade direction $(p<.05)$. $\mathrm{N}-1$ potential mapping showed that, in its development, there is a translocation of its focus from one hemisphere to the other and from the frontal to occipital regions (or viceversa). Furthermore, the foci occupied the fronto- and central-sagittal zones and, in some cases, spread to temporal zones (see Figure 4). In a majority of cases, there was a second negative peak $\mathrm{N}-1$ ' with latency of $37.5 \pm 2.1 \mathrm{~ms}$; furthermore, one of the negative peaks corresponded to the focus of maximum negativity in the frontal region and the other to the occipital region. As with the $\mathrm{N}-1$ potential, the amplitude of the $\mathrm{N}-1$ ' potential was higher in conditions of directed attention in comparison to neutral conditions $(2.1 \pm 0.3$ and $1.5 \pm 0.3$, respectively, $p<.05)$.

The mean amplitude of the $\mathrm{P}-1$ potential in target and neutral conditions was $1.75 \pm 0.26$ and $1.21 \pm 0.19 \mu \mathrm{V}$, respectively $(p<.005)$, and peak latency was $110.3 \pm 6.8$ and $129.4 \pm 8.2 \mathrm{~ms}(p<.05)$. In individual subjects, the $\mathrm{P}$ -1 potential amplitude varied from 0.8 to $2.9 \mu \mathrm{V}$, and latency from 105 to $140 \mathrm{~ms}$. In $93 \%$ of the cases, there was an additional positive $\mathrm{P}-1$ ' potential with a latency of $60.8 \pm$ $5.5 \mathrm{~ms}$, which frequently merged with the spike potential. With directed attention, the amplitude of this potential was also significantly greater than in neutral conditions $(1.6 \pm$ 0.17 and $1.12 \pm 0.15 \mu \mathrm{V}$, respectively, $p<.05)$.

Foci of maximum amplitude of the $\mathrm{P}-1$ potential were located at one of the frontal or occipital cortical zones. In conditions of directed attention, there was a predominance of maximum focus at frontal zones; in neutral conditions the maximum was located at occipital zones and in centraland fronto-sagittal, at the $\mathrm{Cz}$ and $\mathrm{Fz}$ regions. Mapping of the $\mathrm{P}-1$ potential showed that its foci spread simultaneously over several zones in one or both hemispheres, including the $\mathrm{Fz}$ and $\mathrm{Cz}$ sagittal regions (see Figure 4). With the

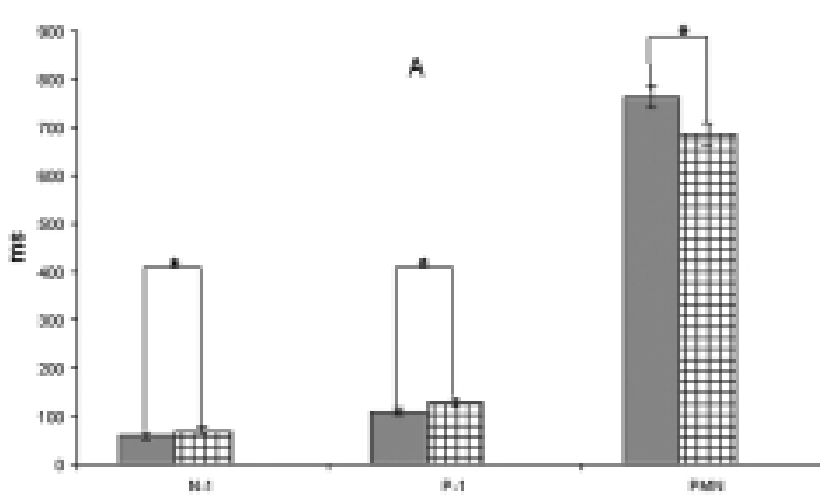

Figure 3. Mean values and mean error of LP value of presaccadic potentials $\mathrm{N}-1, \mathrm{P}-1$, and PMN in two experimental designs. Grey columns $=$ Design I and crossed columns $=$ Design II. $* p<.05$. 
development of the potential, there was a translocation of its foci from frontal zones to parieto-temporo-occipital zones or vice-versa, in correspondence with the second $\mathrm{P}-1$ ' potential. In $69 \%$ of the cases, both in Design I and II, there was a predominance of $\mathrm{P}-1$ and $\mathrm{P}-1$ ' potential foci in the hemisphere contralateral to saccadic direction.

In 10 of the subjects during the period of gaze fixation in the interstimulus pause, there was a slow wave of premotor negativity (PMN), whose parameters were also dependent on the experiment design (Figure 2a, b). The PMN wave began 700 to $900 \mathrm{~ms}$ before the beginning of the saccade. In 4 subjects, this wave was superimposed on rhythmic alpha-diapason oscillations. Furthermore, in neutral conditions, its activeness was more pronounced and more generalized in the cortex and spread from the parietooccipital to frontal and central zones.

In conditions of directed attention, slow negativity started earlier and was $60-105 \mathrm{~ms}$ greater in duration than in

a

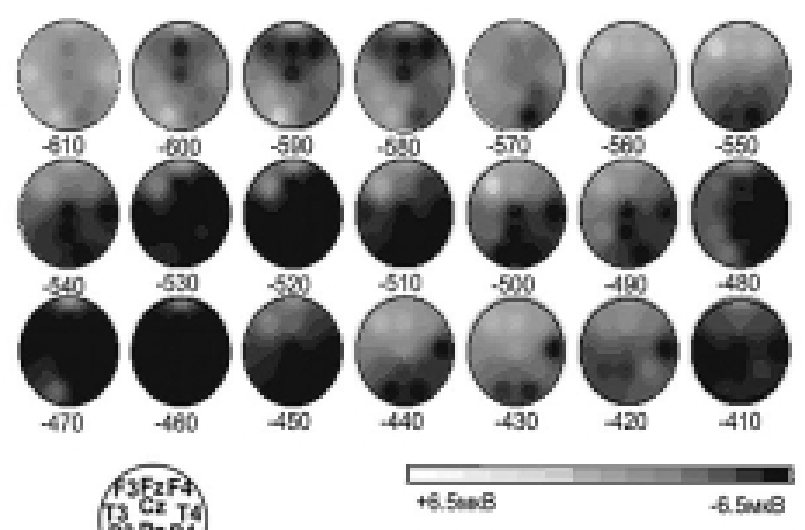

b

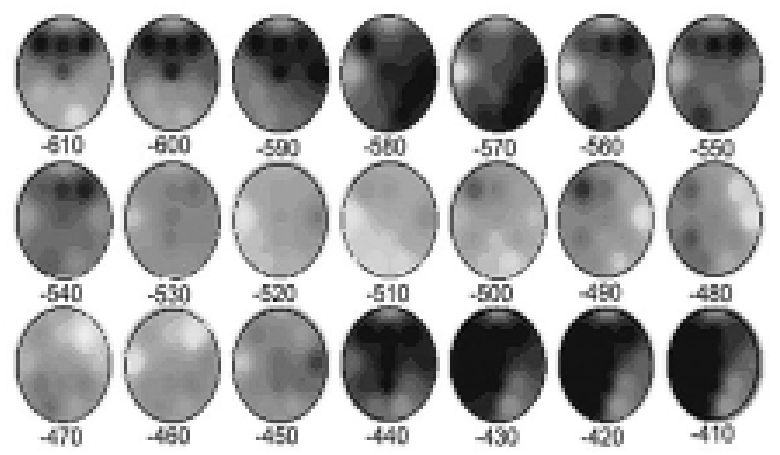

Figure 4. Fragment of mapped amplitude $(\mu \mathrm{V})$ of averaged EEG potentials before saccade to the left of Participant T.E. in experimental Design I at interval $200 \mathrm{~ms}$ before saccade beginning (0 ms). Light foci at interval $130-60 \mathrm{~ms}$ correspond to the P100 potential, at interval $50-0 \mathrm{~ms}$ to the $\mathrm{P}-1$ ' potential, transforming into a pike potential. Dark foci at interval $50-0 \mathrm{~ms}$ correspond to the $\mathrm{N}-1$ potential. $n=40$, mapping increment $=10 \mathrm{~ms}$. neutral conditions $(433.2 \pm 45$ and $398.9 \pm 34$, respectively, $p<.05$, see Figure 2). The latency of the peak of maximum amplitude and the amplitude of the PMN wave was greater in conditions of directed attention $(763.1 \pm 23$, and $686.1 \pm$ $23 \mathrm{~ms}, 1.6 \pm 0.2$ and $1.3 \pm 0.2 \mu \mathrm{V}, p<.005)$. Slow negativity mapping showed that it commenced in symmetrical frontal zones and then spread to central and temporal zones as well as to fronto- and central-sagittal zones (see Figure 4). With the development of negativity, there was a dissemination of its foci to parieto-temporo-occipital zones of both hemispheres and central- and parieto-sagittal zones with further return to frontal zones. During the interstimulus interval there were 2-3 similar translocations of negative foci from anterior to posterior regions and vice-versa. With directed attention, $68 \%$ of the foci with early negativity were predominantly in the left frontal and temporal zones $(p<.001)$.

\section{Discussion}

Despite the existence of various concepts, currently, most researchers consider attention as an aggregate of complex and heterogeneous processes aimed at intensification and acceleration of processes of sensory perception of target stimuli, and central integration, as well as the preparation of a motor response (Coull, 1998; Laberge, 2000; Machinskaya, 2003; Suvorov \& Tairov, 1985).

Posner's (1980) cost-benefit paradigm of covert attention orientation used in the present study permits the simultaneous study of various types of attention: (a) selective attention associated with the assessment of the significance of the stimulus; (b) maintenance or orientation attention during stimulus anticipation, associated with working memory; (c) spatial attention to peripheral target stimulus; and (d) motor attention during preparation and saccade programming in an experiment. The study of the influence of directed attention on the perception of orientation and signal stimuli was presented previously (Slavutskaya, \& Shulgovskiy, 2005).

In the present study, the benefit (the effect or decrease in saccade LP in target conditions) did not occur in all cases or in all the participants. This can be explained by the fact that, in neutral conditions, signal stimuli attract involuntary attention, as practically all the participants had to undergo training not to transfer their gaze to these signal stimuli. The second reason for the absence of the benefit-effect may be the long duration of the interstimulus interval used in the present study $(1000-1300 \mathrm{~ms})$, during which the fading of the "attention trace" may occur (Naatanen, 1998). It has been shown that the optimum interval for the maintenance of spatial attention is $500 \mathrm{~ms}$ (Posner, 1980), but this type of experiment does not permit the study of slow bioelectric activity related to anticipation and preparedness.

In the present study, the comparison of presaccadic EEG potentials in target and neutral conditions was made only in those cases where the benefit-effect was sufficiently 
pronounced. Analysis of the data showed that, in target conditions, there is an increase in amplitude and a decrease in latency of the presaccadic $\mathrm{P}-1$ and $\mathrm{N}-1$, initiation potentials. This may be evidence of the fact that covert attention orientation leads to the intensification and acceleration of saccadic generation processed at the initiation stage of motor command.

Analogous initiation potentials were first described before manual reactions- $-\mathrm{N}-10$ and P50 (Shibasaki, Barret, Halliday, \& Halliday, 1980). Previously, we have been able to distinguish quick initiation potentials- $\mathrm{P}-1(100)$ and $\mathrm{N}$ $-1(50)$ - preceding visually evoked saccades using selective EEG averaging before the saccades, whose LP varies within the narrow diapason of $20-40 \mathrm{~ms}$ (Slavutskaya \& Shulgovsky, 2002, 2003). In most cases, the $\mathrm{N}-1$ potential was localized at the parieto-occipital zone contralateral to saccade direction. Clinical and neurophysiologic studies on primates have shown the role of parietal oculomotor fields (LIP zones) in the initiation of visual evoked saccades (Andersen \& Gnadt, 1989; Gaymard, Ploner, Rivaud, Vermersch, \& Pierro-Deseilligny, 1998; Platt \& Glimcher, 1997). The present study has also shown the predominance of foci of the $\mathrm{N}-1$ potential in the contralateral hemisphere. However, they have been located in both parieto-occipital as well as frontal zones of both hemispheres and during the development of the potential transposed from anterior cortical regions to posterior regions and vice-versa, and spreading to fronto-sagittal and temporal zones. Likewise, a similar $\mathrm{N}-1$ potential topography was previously achieved in an experimental design with a 200-ms interstimulus pause (gap) (Slavutskaya \& Shulgovsky, 2002), in which there was also a decrease in saccade latency (gap-effect) in comparison to stimuli without pause (step). As expected, the nature of the gap-effect is also determined by the involvement of attention in the process of saccadic programming: in the gap-design, the initial stage of saccade programming from disengaging of attention from the fixation point occurs in the interstimulus interval prior to the involvement of visual aim (Fischer \& Breitmeyer, 1987).

The $\mathrm{P}-1$ initiation potential corresponds to the previously described premotor positive wave occurring at $100-250$ ms before saccade beginning (Deecke, Heis, Kornhuber, Lang, \& Lang, 1984; Jagla \& Zikmund, 1994) or the quick P -50 wave before hand movement (Shibasaki, 1980). The nature of premotor positivity remains debatable. Various authors suggest that this wave may be a reflection of either saccade programming processes and their initiation or the inhibitory processes of relaxation of cortical structures after decision-making (Deecke et al., 1984; Jagla \& Zikmund, 1994). Shibasaki and colleagues (1980) suggested that premotor positivity may be related to the process of inhibition, necessary for the suppression of movement of the contralateral extremity (or the other direction, in the case of eye movement) as, in most cases, it is ipsilaterally located.
Previously, we carried out the comparison of parameters and topography of the $\mathrm{P}-1$ potential depending on the magnitude of the saccade LP in the gap and step paradigms (Slavutskaya \& Shulgovsky, 2002, 2003). The findings allow the suggestion that the $\mathrm{P}-1$ potential is of mixed genesis. It reflects processes both of saccadic programming (decision making and movement initiation) and the inhibition of saccades of the opposite direction. In the present study, the foci of the $\mathrm{P}-1$ potential as well as the $\mathrm{N}-1$ potential were widespread within the cortex and transposed from frontal, fronto-sagittal and central zones to parieto-occipital (or viceversa), and spread to temporal zones. Such potential topography may reflect the activation of the primary oculomotor fields of the frontal, parieto-occipital and temporal cortices as well as the fronto-parietal network of spatial attention rendering a modulating influence on the circuits and centers of saccade initiation (Bon \& Lucchetti, 1992; Bruce, 1990; Coull, 1998; Goldberg \& Segraves, 1989; Laberge, 2000; Machinskaya, 2003; Posner, 1980; Suvorov \& Tairov, 1985).

The present study revealed additional initiation potential components: $\mathrm{P}-1$ ' and $\mathrm{N}-1$ '. The $\mathrm{P}-1$ ' potential often merged with the spike potential or divided the negative initiation potential into two waves, $\mathrm{N}-1$ and $\mathrm{N}-1$ ' (see Figure 2, a, b). Similar negative waves were distinguished by Arezzo and Vaughan (1980) before movement in extremities in subdural registration in monkeys and noted as $\mathrm{N} 2 \mathrm{a}$ and $\mathrm{N} 2 \mathrm{~b}$. These authors suggested that the first potential is related to the initiation of movement, whereas the second one reflects signals of afferent feedback from extension and joint receptors. It is possible that, in a condition of directed attention, the $\mathrm{N}-1$ ' and $\mathrm{P}-1$ ' potentials also reflect signals of afferent feedback in the form of proprioceptive signals from oculomotor muscles as well as the "efferent copy" of the motor command from brain stem oculomotor structures.

In contrast to our previous studies, the present study showed a predominance of the $\mathrm{P}-1$ and $\mathrm{P}-1$ ' potentials not in the ipsilateral, but in the contralateral hemisphere to saccade direction. Probably, in the conditions of directed attention of the Posner (1980) paradigm, the process of inhibition of saccades of opposing direction is tonic in nature and occurs before the period of anticipation of the target stimulus. Similar results were achieved in the study of Richards (2003), using signal stimuli prediction of saccade direction. This study also revealed the localization of foci of premotor positivity in the contralateral frontal cortex.

In the present study, we have shown the predominance of initiation potential foci in front- and central-sagittal zones. The leading zones of saccadic planning are located within the medial surface of the frontal lobes: the dorsomedial prefrontal field (DMFC), the supplementary oculomotor field (SEF), as well as the oculomotor field of the cingular gyrus (ACC) (Bon \& Lucchetti, 1992; Gaymard et al., 1998; Pierrot-Deseiligny, Israel, Berthoz, Rivaud, \& Gaymard, 
1993). It is a known fact that there are widespread anatomic and functional connections of the fronto-medial cortex with the prefrontal, parietal, and motor cortex and the activating systems of the limbic and straital systems (Gaymard et al.,1998; Middleton \& Strick, 2000; Schlag-Rey \& Schlag, 1989; Suvorov \& Tairov, 1985).

The data show that, in conditions of covert attention orientation during saccade initiation, the leading oculomotor zones of the frontal and prefrontal cortices are activated. Perhaps the influence of directed attention is carried out through additional descending circuits of saccade initiation from the cortical frontal oculomotor fields to the brainstem saccadic generator, bypassing the superior colliculi (Gaymard et al., 1998).

The present study has revealed the influence of directed spatial attention not only on processes of saccade initiation, but also on processes of motor preparation during the interstimulus interval. This was reflected in the intensification and earlier start of the slow premotor negative wave in target conditions in comparison to neutral conditions. Slow premotor negativity has been studied in detail both before hand movement and saccades for the past 30 years (Barret, Shibasaki, \& Neshige, 1986; Batuev, 2001). It is suggested that it is associated with various pre-trigger processes of motor programming such as attention, motivation, motor readiness, and time countdown. In contrast to our previous studies with visually evoked saccades and antisaccades, the present study did not reveal two clearly defined components of premotor negativity: the early PMN1 wave of frontal localization and the late PMN2 with parieto-occipital localization, which we suggest are equivalents of the $\mathrm{O}$ - and E-components of the contingent negative variation or readiness potential before hand movement (Batuev, 2001; Barret et al., 1986).

It may be suggested that the slow presaccadic negativity that develops during the interstimulus interval is a correlate of orientation or sustained attention (Coull, 1998), the nature of which is intimately related to storing spatial information about the localization of the visual target ("Attention trace" or "motor image") in the working memory (Naatanen, 1998). The relationship between the frontal and parietal oculomotor fields with the working memory is known from clinical data, PET, and fMRI, and has been demonstrated in studies of the activity of single neurons in primates, showing their tonic activity during the interstimulus interval (Gaymard et al., 1998; Posner, 1980).

It is evident that, in the target conditions of Posner's (1980) paradigm, maintaining attention to the spatial localization of the PTS during the interstimulus interval provides better efficacy to the response reaction, including the activation of oculomotor structures and decision-making (Laberge, 2000). Furthermore, there is periodic involvement of the leading frontal and parietal cortical zones as "sources" of spatial attention and saccadic control. We suggest that the spatialtemporal changes in the premotor negative wave in the present study are a sign of the circulation of nervous impulses (attention traces) within fronto-parietal cortical networks, as a reflection of sustained attention (Naatanen, 1998). The distribution of negativity foci at sagittal zones of the frontal and parietal cortices may also be evidence of the involvement of fronto-medio-thalamic modulating and the thalamo-parietal associative systems in maintaining attention during anticipation of target stimuli (Laberge, 2000; Machinskaya, 2003; SchlagRey \& Schlag, 1989; Suvorov \& Tairov, 1985).

\section{Conclusion}

The use of the Posner (1980) cost-benefit paradigm has revealed the influence of attention processes on various stages of visually evoked saccade preparation and is reflected in the parameters of cortical averaged potentials. In conditions of directed attention, an increase in amplitude and a decrease in latency of the $\mathrm{P}-1$ and $\mathrm{N}-1$ initiation potentials, and an intensification of slow negativity in the interstimulus interval after switching off the signal stimuli and during the anticipation of target stimuli has been demonstrated.

The spatial-temporal changes of prosaccadic potentials may be evidence of the fact that covert attention orientation during the period of motor preparation and saccade initiation leads to intensification of the activity of the fronto-parietal networks of saccadic control, including the fronto-mediothalamic and thalamo-parietal networks that modulate selective attention systems.

\section{References}

Andersen, R.A., Gnadt, J.W. (1989). Posterior parietal cortex. In R. Wurts R. \& M. Goldberg (Eds.), The neurobiology of saccadic eye movements (pp. 315-335). Amsterdam, Elsevier Science.

Arezzo, J., \& Vaughan, H.G. (1980). Intracortical sources and surface topography of motor potential in the monkey. Progress of Brain Research, 54, 77.

Barret, G., Shibasaki, H., \& Neshige, R. (1986). Cortical potentials preceding voluntary movement: Evidence for three periods of preparation in man. Electroencephalography and Clinical Neurophysiology, 63, 327-339.

Batuev, A.C. (2001). Stanovlenie psikhofiziologii v SanktPeterburgskom Gosudatstvennom Universitete [The establishment of psychophysiology in the Saint-Petersburg University] Zhurnal Vysshei Nervnoi Deyatelnosti, 51, 12-16.

Bon, L., \& Lucchetti, C. (1992). The dorsomedial frontal cortex of the Macaca monkey: Fixation and saccade-related activity. Experimental Brain Research, 89, 571-580.

Bruce, C.J. (1990). Integration of sensory and motor signals in primate frontal eye fields. Journal of Neurophysiology, 64, 489-508.

Coull, J.T. (1998). Neural correlates of attention and arousal insights from electrophysiology, function neuroimaging and psychopharmacology. Progress in Neurobiology, 55, 343-361. 
Deecke, L., Heis, B., Kornhuber, H.H., Lang, M., \& Lang, W. (1984). Brain potentials associated with voluntary manual tracing . Annual of New York Academy of Science, 374, 361.

Fischer, B., \& Breitmeyer, B. (1987). Mechanism of visual attention revealed by saccadic eye movement. Neuropsychology, 25, 7378.

Gaymard, B., Ploner, C.J., Rivaud, S., Vermersch, A.I., \& PierroDeseilligny, C. (1998). Cortical control of saccades. Experimental Brain Research, 123, 159-163.

Goldberg, M.E., \& Segraves, M.A. (1989) The visual and frontal cortex. Neurobiology of saccadic eye movements. Reviews of Oculomotor Research, 2, 283-310.

Jagla, F., \& Zikmund, V. (1994). Differences in eye movement related potentials with visually triggered horizontal and vertical saccades. In G. d'Ydwalle \& J. Van Rensbergen (Eds.), Visual and oculomotor functions. Advances in eye movement research. (pp. 19-30). Amsterdam: Tocio.

Laberge, D. (2000). Networks of attention. In M.S. Gazzaniga (Ed.), The new cognitive neurosciences (pp. 711-724). Cambridge, MA: MIT Press.

Mangun, G.R., Jha, A.P., Hopfinger, J.B., \& Handy, T.C. (2000). The temporal dynamics and functional architecture of attentional processes in human extrastriate cortex. In M.S. Gazzaniga (Ed.), The new cognitive neurosciences (pp. 701-709). Cambridge, MA: MIT Press.

Machinskaya, R.I. (2003). Neirofiziologicheskie mekhanizmi proizvolnogo vnimaniya (analiticheskiy obzor). (Neurophysiological mechanisms of voluntary attention: Analytical review). Zhurnal Vysshei Nervnoi Deyatelnosti, 53, 133-150.

Middleton, F., \& Strick, P.L. (2000). Basal ganglia and cerebellar loops: Motor and cognitive circuits. Brain Research Reviews, $31,236-250$.

Naatanen, R. (1998). Vnimamie i funktsii mozga. (Attention and the brain function). Moscow University Press, 559.

Platt, M.L., \& Glimcher, P.W. (1997). Responses of intraparietal neurons to saccadic targets and visual distractors. Journal of Neurophysiology, 78, 1574-1589.

Pierrot-Deseiligny, C., Israel, I., Berthoz, A., Rivaud, S., \& Gaymard, B. (1993). Role of the different frontal lobe areas in the control of the horizontal component of memory-guided saccades in man. Experimental Brain Research, 95, 166-171.

Posner, M. (1980). Orienting of attention. Journal of Experimental Psychology, 32, 3-21.

Richards, J.E. (2003). Cortical sources of event-related potentials in the prosaccadic and antisaccadic task. Psychophysiology, 6, 878-894.
Rizzolatti, G., Riggio, L., Dascola, L., \& Umilta, C. (1987). Reorientation attention across the horizontal and vertical meridians: Evidence in favor of a premotor theory of attention. Neuropsychologia, 25, 31-40.

Robinson, D.L, Bowman, E.M., \& Kertzman C. (1995). Covert orienting of attention in macaques. II. Contribution of parietal cortex. Journal of Neurophysiology, 74, 257 -276.

Rutman, E.M. (1979). Vyzvannye potentsiali $v$ psikhologii $i$ psikhofiziologii (Evoked potentials in psychology and psychophysiology). Moscow: Nauka.

Slavutskaya, M.V., Solovieva, E.V., \& Shulgovskii, V.V. (2001). Velichina latentnogo perioda sakkadicheskikh dvizheniy glaz $\mathrm{v}$ usloviyakh veroiyatnostnogo prediyavleniya zritelnoi tseli

(Saccadic latency during probability presentation of a visual target in man). Zhurnal Vysshei Nervnoi Deyatelnosti, 51, 106-109.

Slavutskaya, M.V., \& Shulgovskii, V.V. (2002). Medlennye negativnye potentsiali golovnogo mozga cheloveka $\mathrm{v}$ period fiksatsii i podgotovki sakkad na zritelnye stimuli [Slow negative cortical potential during the eye fixation and preparing of visualtriggering saccades in man]. Zhurnal Vysshei Nervnoi Deyatelnosti, 52, 551-562.

Slavutskaya, M.V., \& Shulgovskii, V.V (2003). Pozitivni potentsiali golovnogo mozga cheloveka na razlichnikh etapach podgotovki zritelno-vyzvannoi sakkadi (Positive potentials of human brain at different stages of preparation of visually triggering saccades). Zhurnal Vysshei Nervnoi Deyatelnosti, 53, 341-350.

Slavutskaya, M.V., \& Shulgovskii, V.V. (2005). Siemina T.K. Vliyanie napravlennogo vnimaniya na potentsiali golovnogo mozga pri veroiatnostnom prediyavlenii zritelnikh stimulov (Directed attention influence on human brain potentials during probability visual stimulation). Zhurnal Vysshei Nervnoi Deyatelnosti, 55, 796-805.

Suvorov, N.F., \& Tairov O.P. (1985). Psichofiziologicheskie mechanizmi napravlennogo vnimania (Psychophysiological mechanisms of directed attention). Leningrad: Nauka.

Shibasaki, H., Barret, G., Halliday, E., \& Halliday A. (1980). Components of the movement-related cortical potential and their scalp topography. Electroencephalography and Clinical Neurophysiology, 4, 213 - 226.

Schlag-Rey, M., \& Schlag, J. (1989). The central thalamus. In R. Wurts \& M. Goldberg (Eds.), The neurobiology of saccadic eye movements (pp. 361-390). Amsterdam: Elsevier Science.

Received December, 5, 2006

Revision received June, 12, 2007

Accepted August, 8, 2007 